\title{
About the Artist: Solomon Enos
}

So olomon Robert Nui Enos is a native Hawaiian artist who was born and raised on the west side of O'ahu, in Mākaha Valley. His family is active in the community: his father, Eric, is founder of the Ka'ala Cultural Learning Center; his mother, Shelly, works at the Wai'anae Coast Comprehensive Health Center; his brother Kamuela works at $\mathrm{MA}^{\prime} \mathrm{O}$ Organic Farms and was recently named as a commissioner for President Obama's Advisory Committee for Asian Americans and Pacific Islanders; his brother Kanoe is a social worker; and his brother Kanohi is an artisan and woodworker who makes indigenous tools and imple-

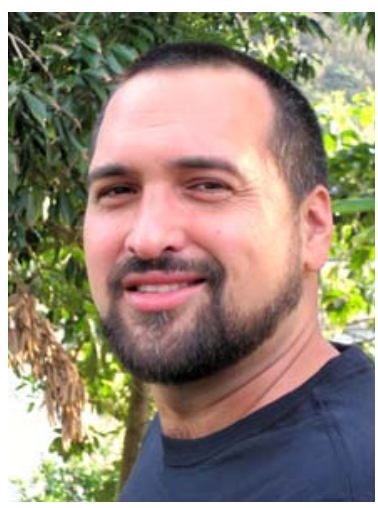

Photo by Meredith Desha Enos ments. Solomon is proud of his family and credits them for much of his original inspiration and for their support for his becoming an artist.

Solomon received his first commission as a sixth grader, illustrating curriculum materials for younger elementary students at Mākaha Elementary, and he has been on a roll ever since. Among other books, he illustrated Akua Hawai'i: Hawaiian Gods and Their Stories (Bishop Museum Press, 2005 ) and the centennial edition of The Epic Tales of Hi'iakaikapoliopele (Awaiaulu Press, 2006). Solomon has worked for and with many organizations on O'ahu's Leeward side, including Mākaha Elementary School, Nānākuli Intermediate School, MA'O Organic Farms, Ka'ala Cultural Learning Center, Hoa'āina O Makaha, and Wai'anae Coast Comprehensive Health Center. Each of these organizations has given Solomon an opportunity to see in concrete ways how art, the land, and the people can all take care of and inspire each other. He has also done artwork for the Sheraton Waikiki, Royal Hawaiian Hotel Royal Beach Tower, AulaniDisney Hawai'i Hotel, and other commercial spaces. For more information, see http://www.solomonenos.com/

The art featured in this issue can be viewed in full color in the online version of The Contemporary Pacific via Project MUSE. 


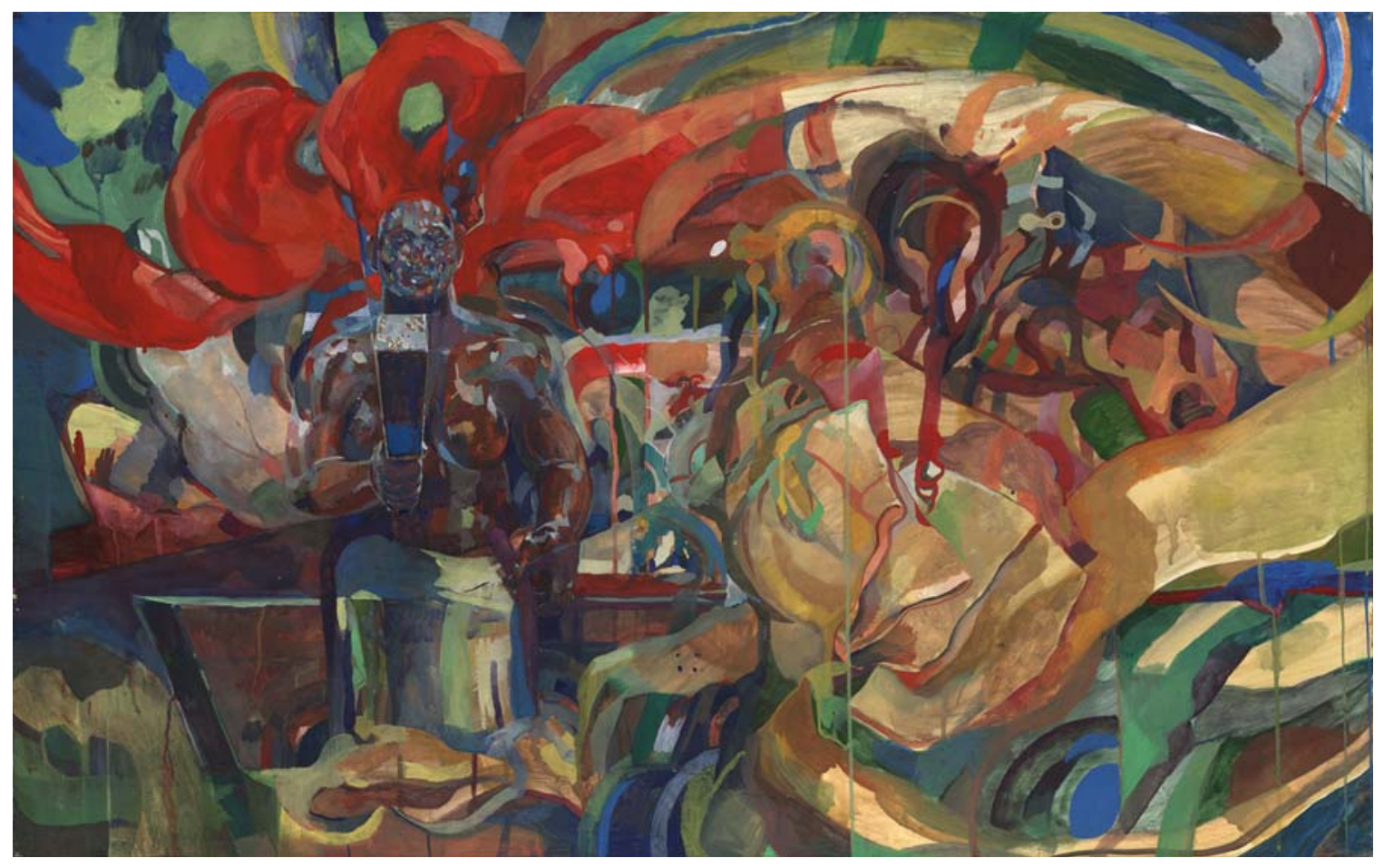

Kapa Maker, by Solomon Enos. 2004.

Gouache on 30 " $\times 48$ " canvas.

This is a visual representation of the mana or energy that goes into the making of kapa or barkcloth. 


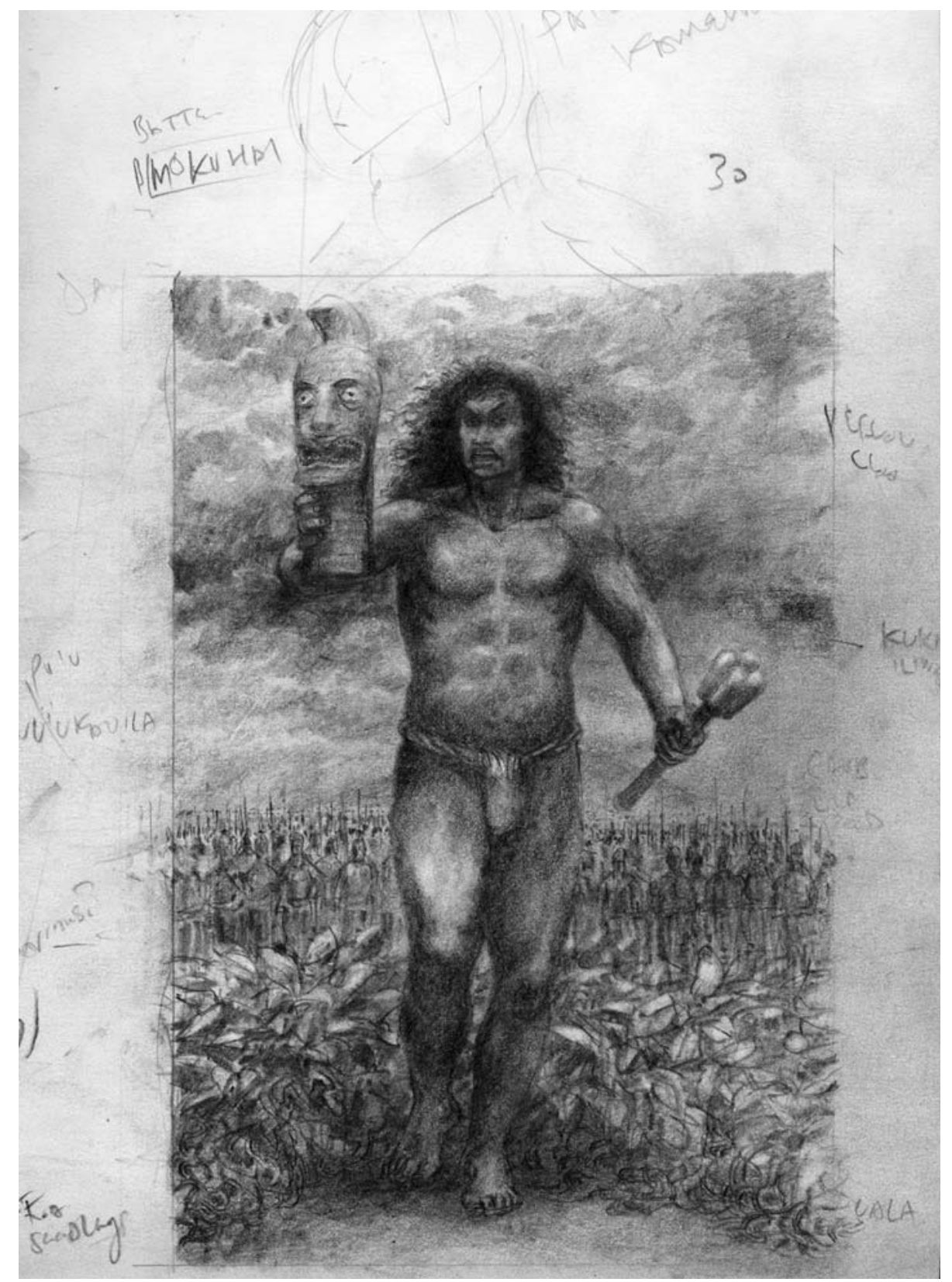

Kamehameha, by Solomon Enos. 2008.

Pencil on I I" X I4" bristol board. This image of ali'i nui Kamehameha I going to war was drawn for a forthcoming book written by Kimo Armitage titled Me'e Hawai $i$, Heroes of Hawai $i$. 


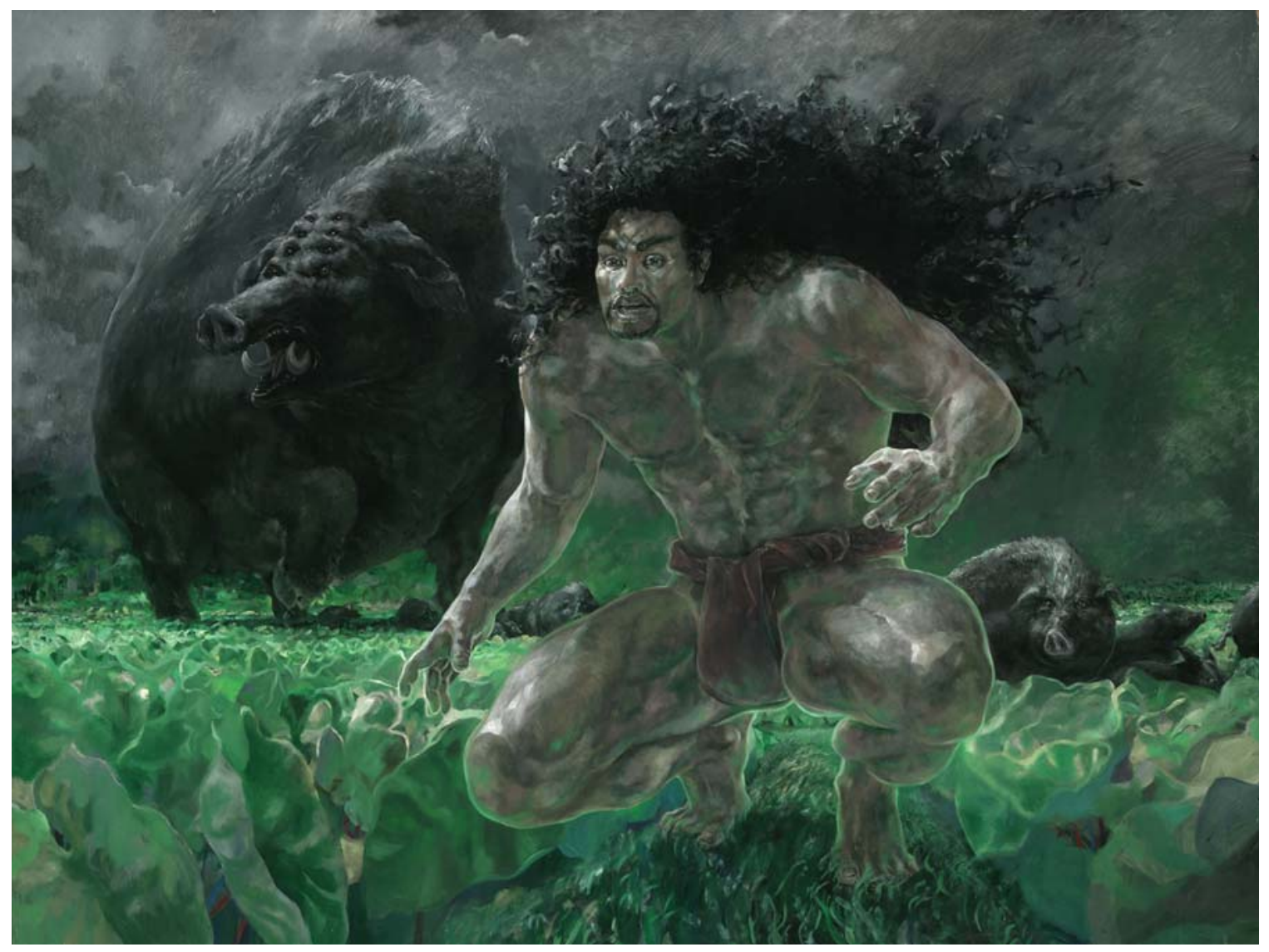

Kamapua' $a$, by Solomon Enos. 2005. Oil on $36 " \times 48^{\prime \prime}$ Masonite. This painting depicts the Hawaiian god of fertility. 


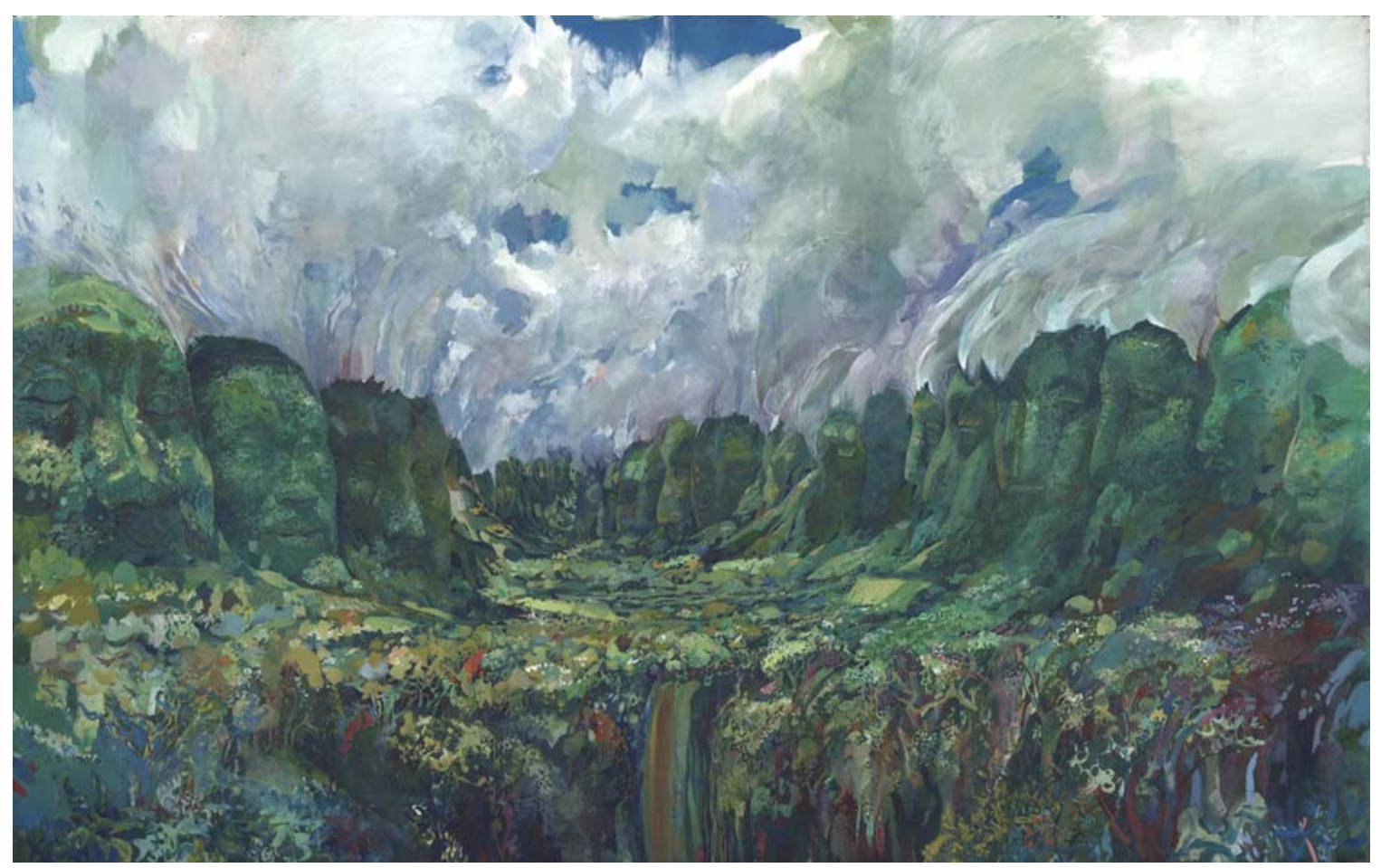

Alo 'Āina, by Solomon Enos. 2004.

Gouache on $30^{\prime \prime} \times 48^{\prime \prime}$ canvas.

This is a visual representation

of the concept of sentient landscapes. 


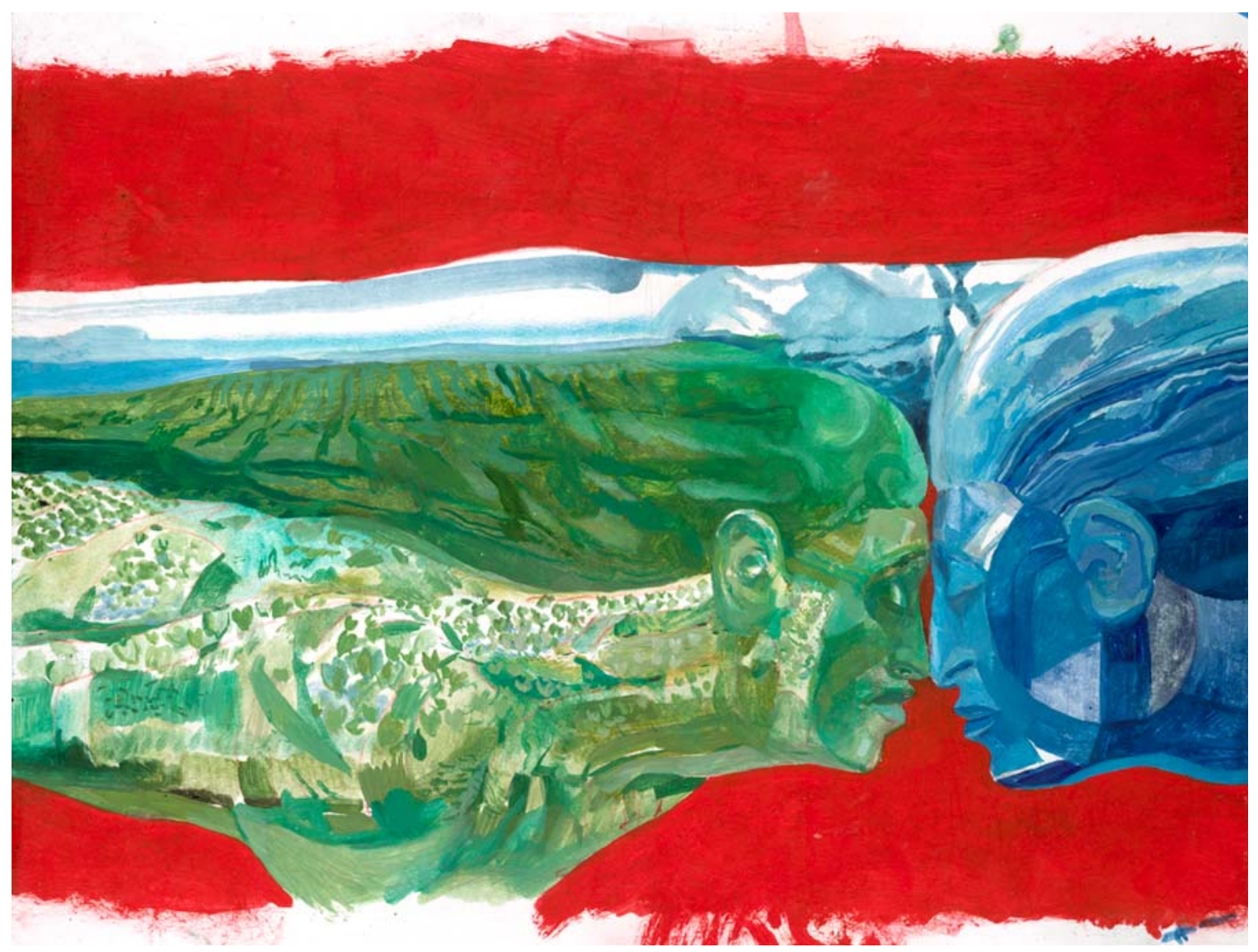

Hāloa, by Solomon Enos. 2003.

Oil on I I" X I4" bristol board.

This image is from a book of the same title written by Kimo Armitage and Sharon Odom, published by Kamehameha Schools Publishing (2006). 


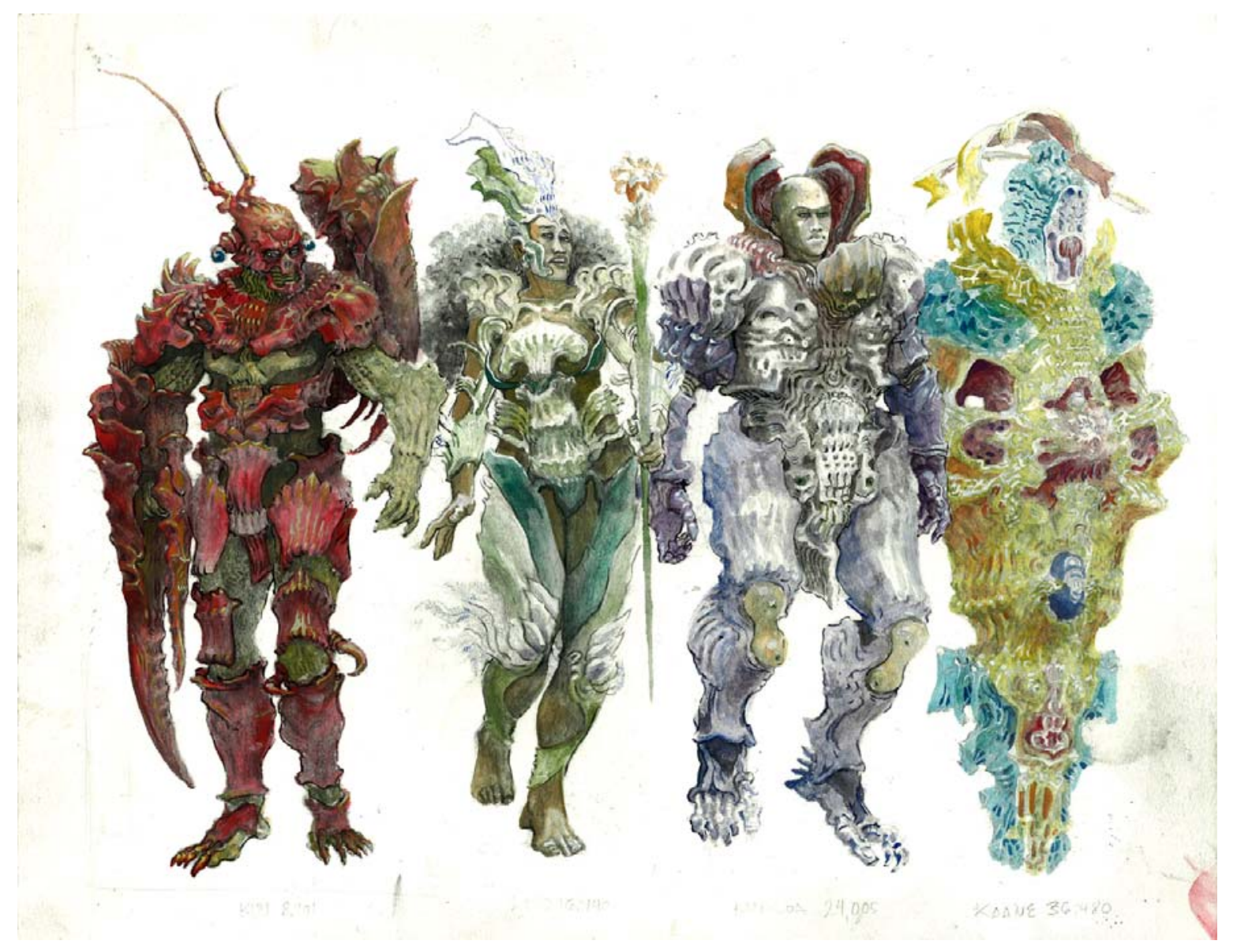

The 40,000 Years of Polyfantastica, by Solomon Enos. 2008.

Gouache on I I" X I4" bristol board.

In this study for a project Enos is working on called Polyfantastica, each figure represents Io,००० years of fictional history based on a Polynesian society. 


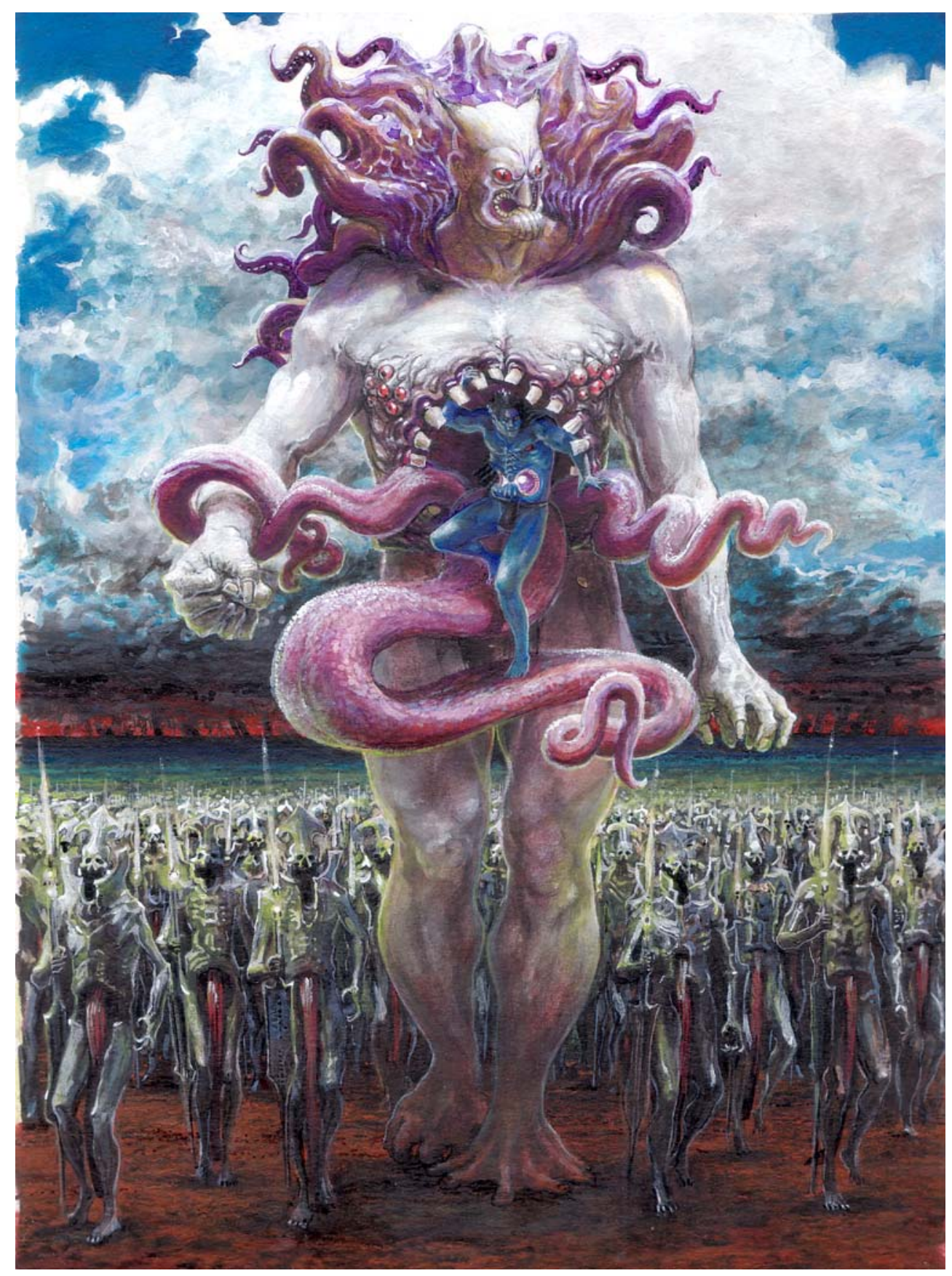

Hulomo, by Solomon Enos. 2007.

Acrylic on I I" X I4" bristol board. This will be the cover of a forthcoming graphic novel Enos is writing, set within the fictional Polynesian history setting called Polyfantastica. 


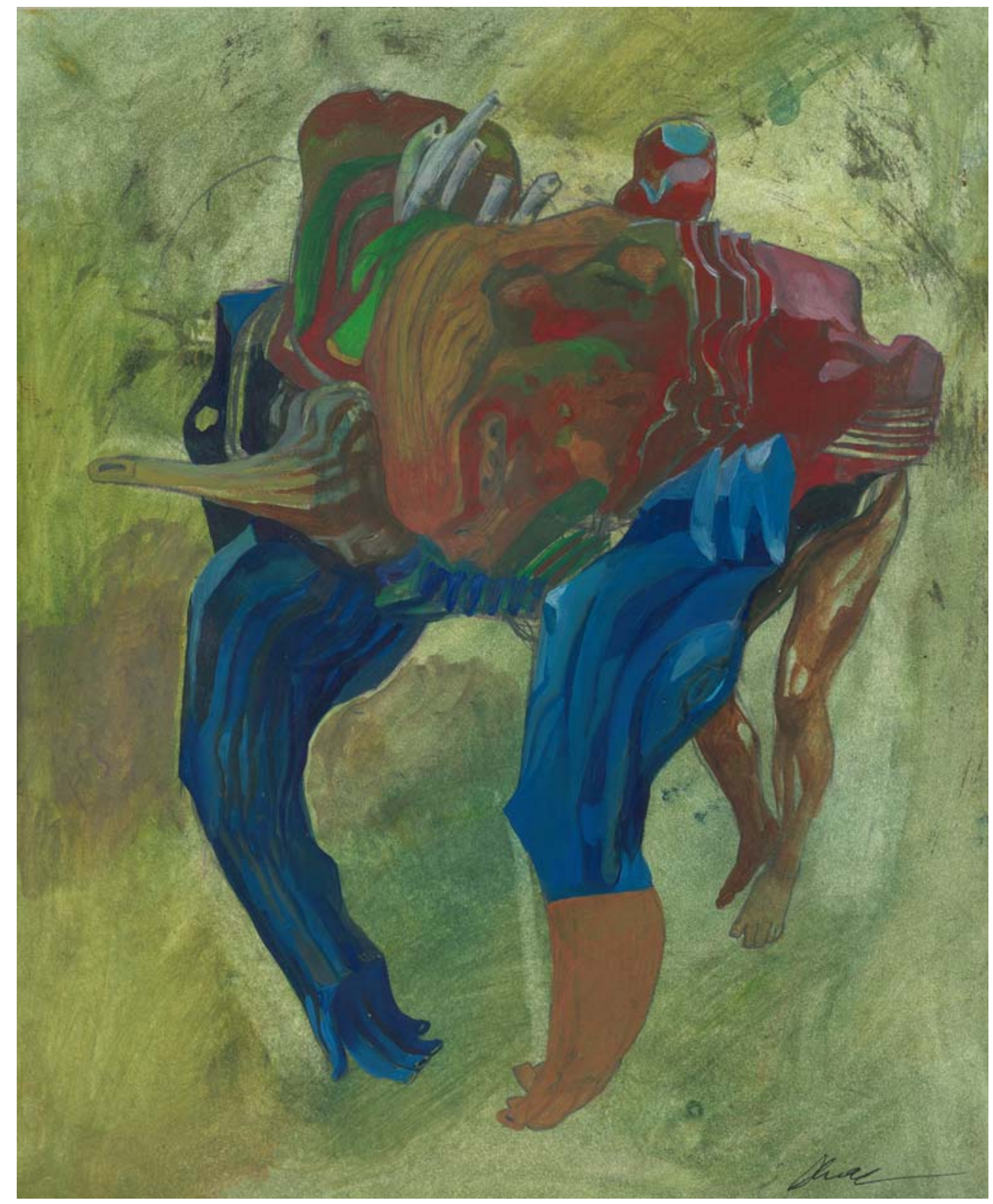

Intergalactic Human Seed, by Solomon Enos. 2004.

Oil on I I" X I4" bristol board.

This is a study for a future painting in the sciencefictional Polynesia setting called Polyfantastica. 